rially different, they ought to be demonstrated, not by attempting operations for which the indications are dubious, and which, therefore, cannot be expected to become common, but by showing that hospitals are decidedly healthier and cures decidedly more rapid and more certain in ordinary cases. Some difficulty seems to have stood in the way of affording such evidence in Edinburgh. There ought to be no such difficulty in London, and the beginning of a new year affords a favourable opportunity for commencing the comparison. - I hope the importance of the subject, and my own anxiety to do my duty in connexion with it, may relieve me of any charge of presumption in making the suggestion. I am, Sir, yours, \&c.,

Great Cumberlanda-place, Dec.11th, 1877.

T. HOHMES.

THE

MEDICAL ASPECTS OF TOTAL ABSTINENCE. To the Editor of The LaNCET.

SIR,-It is much to be regretted that Mr. Brudenell Carter's attempts to become a total abstainer have ended in failure. The advocacy of his pen, to say nothing of the force of his personal example, is a loss to the cause of temperance.

One may, however, be allowed to discount the loss. For, after all, his letter goes to prove nothing more than that he, as an individual, is unable to accomplish his work without the assistance of "very weak whisky-and-water-the genuine article-well matured by keeping." For the purpose of illustration in this matter, one man is as good as another. For four years $I$ have succeeded in doing my work, not only without detriment to myself, but with improved health, unaided by any alcoholic stimulant. My work is no trifle, covering, as it does, that of a busy general practitioner, together with the cares and anxieties of hospital work. Like most men in such a position, I have to combine as best I can in my work all the "specialisms" of the day. I may, then, set my case against Mr. Brudenell Carter's, and, so far, we may cry quits! But when we come to discuss the broader question as to whether total abstinence from alcohol, or moderate drinking, is best for the community at large, we launch out on a discussion to which neither the personal experience of Mr. Brudenell Carter nor my own can contribute much. Let us first eliminate from the community certain classes. The habitual drunkards, Mr. Brudenell Carter will, no doubt, admit, must be treated by total abstinence. Next, the vast multitude of total abstainers who, like myself, have become so for example sake. Then the smaller number of persons, who, for one disease or another, have been obliged to renounce stimulants. Of the residue it is impossible to say how many can live and work without stimulants, because they have never tried the experiment. Judging from what one knows, one would think that a very vast number would not only succeed, if they tried, but would in every way be better off. So, too, some eminent members of our profession seem to think. Dr. Brunton, before the Lord's Committee, is reported to have said, "If a man eats well and sleeps well he does not require alcohol, and he is better withont it." Dr. Burdon-Sanderson said, "My belief is that, upon the whole, the human race would be situated just as favourably if the use of alcohol did not exist." Sir William Gull said, "I should like to say that a very large number of people in society are dying day by day poisoned by alcohol, but not supposed to be poisoned by it."

I agree with Mr. Brudenell Carter that we have plenty of facts to go upon without pinning our faith to the result of laboratory work, or the fallacies of chemists. We know as a fact that, supposing alcohol were to-morrow eliminated from all dietetic purposes, and restricted only to medicinal uses, we might inflict a minute evil on a very small minority, but that the vast majority of the people would be immensely benefited; nay, more, that thousands of lives would be saved, many crimes avoided, and pauperism diminished. As individual members of a profession, whose great aim ever has been to help in effecting these objects, I think it is our bounden duty to do all we can to diminish intemperance. If, then, with a wise discrimination, we can induce people to become total abstainers, we not only place them in a position of safety, but we provide in each one so abstaining a point from which temperance principles radiate; for $I$ hold that one wise total abstainer is worth any number of platform speeches or temperance sermons. In my humble opinion Mr. Brudenell Carter has taken up his pen too soon. We are not yet, either as a profession, or a nation, so far gone in total abstinence as to need a crusade against it. I am Sir, your obedient servant,

Devonport, November, 1877.

$$
\text { William PadL Swain, F.R.C.S. }
$$

\section{ON THE USE OF THE SUBCUTANEOUS SAW IN OPERATIONS FOR CLOSURE OF THE HARD PALATE. \\ To the Editor of ThE LANCET.}

SIR,-In your issue of September 22nd, 1877, I notice the report of a case of cleft through the hard and soft palate, for the relief of which Mr. Henry Smith, at the King's College Hospital, employed the plan of operation suggested by the late Sir William Fergusson, by which method the cleft in the hard palate is closed by segments of bone detached by the chisel from the sides of the palate, drawn to the median line, and secured in position by suture.

In the report the statement is made that occasionally some necrosis of the bone has occurred at the point of division, and that failure has followed this method of operation in consequence of severe bæmorrhage.

Having encountered both of these unfarourable conditions in performing uranoplasty by this plan, I determined to abandon the use of the chisel and employ the saw for the purpose of dividing the bone. In February of this year I employed it for the first time, and with complete success. With this instrument the section of the bone is accurately and rapidly made. The bone is not splintered, the segments being separated entire, and the laceration of the soft structures is very slight.

I have found the saw devised by Mr. Adams for section of the femur to be well adapted for the purpose. In using it, a small incision is made in the soft palate at the line of attachment to the hard palate, the saw is introduced, and the bone is divided from behind forwards, care being taken to follow the line of incision previously made through the soft structures, mucous membrane and periosteum, covering the hard palate.

The spaces left on each side are packed with lint, as suggested by Mr. Smith.

I venture to express the belief that the use of the saw in place of the chisel will perfect the method of operation suggested by the late Sir William Fergusson, and which is, without doubt, the best that can be employed for the relief of cleft of the hard palate.

Very respectfully, your obedient servant,

Philadelphia, Pa., Oet. 21st, 1877. J. Ewing Mears, M.D.

\section{attedical a}

Royal College of Surgeons of England. The following Members having passed the required examination on the $22 \mathrm{nd}$, 23rd, and 24 th ult., were, at a meeting of the Council on the 13th inst., duly admitted Fellows of the College:-

Amphlett, Edward, M.B., Leamington.

Archer, W. Gammon, MB. Birmingham.

Cantlie, James, M.A, and M. B. Dufftown, Banffshire.

Clarke, J. St 'Thomas, L.R.C.P. Lond., Leicester.

Dent, $\mathrm{C}$.

Elliot, N. Bruce, L.R.C.P. Lond., Denmark-hill.

Elliot, N. Bruce, L.R.C.P. Lond., D

Paley, W. Edmund, T. R.C.P. Lond, Peterborough.

Paley, W. Edmund, L.R.C.P. Lon

Verco, J. Cooke, Adelaide, South Australia.

Three candidates failed to satisfy the Court of Examiners, and were referred for twelve months' further professional study.

UNIVERSITY OF LONDON.-The following candidates passed the recent B.S. Examination for Honours:Vereo, Joseph Cooke, Mr.D. (Scholarship and Gold Medal), St. Bartholomew's Hospital.

symonds, Charters James (Gold Medal), Guy's Hospital. 